\title{
0 cristal, o ferro e o sal: recursos minerais do antigo Guairá (1557-1632), atual estado do Paraná
}

\author{
Jefferson de Lima Picanço \\ Depto. Geoc. Aplic. ao Ensino, Inst. Geociências, Universidade \\ Estadual de Campinas.E-mail: jeffpicanco@ige.unicamp.br \\ Maria Jose M. de Mesquita \\ Departamento de Geologia, Setor de Ciências da Terra, Universidade \\ Federal do Paraná. E-mail:mj_mesquita@ufpr.br
}

\footnotetext{
*Este artigo deve ser referido como segue:
}

Picanço J. de L., Mesquita M. J. M. de 2010. 0 cristal, o ferro e o sal: recursos minerais do antigo Guairá (1557-1632), atual estado do Paraná. Terræ Didatica, $6(2): 67-75<$ http:// www.ige.unicamp.br/ terraedidatica/>

\begin{abstract}
The current research deals with the importance of mineral resources to the success and failure of the spanish colonization at the ancient Guairá. The Guairá, currently Paraná state, was a former spanish province that belonged to the colonial Paraguay. The spanish villas and Jesuitical Reductions were destroyed by the paulistas, in 1629-32. The search for metal ore was important at the Guaira's settlement, just as in other regions of the Spanish America. The metals were virtually absent, and the spaniards had explored Yerba mate (Ilex paraguaiensis) as economical resource. The main mineral resources at that time were amethyst and iron. The jesuits also reported the existence of salt deposits in Guairá. The amethyst ore provoked a rebellion in Ciudad Real del Guaira in 1569. The iron was exploited from laterite by the spaniards and Jesuitic's Reductions. The former siderurgical experience of the spaniards was important for the incipient iron industry developed. The absence of precious metal resources and the paulistas dispute for native's labour took the evacuation of the Guairá by spaniards.
\end{abstract}

\section{KEYWORDS Mineral resources, South America, Guairá, amethyst, iron.}

RESUMO A presente pesquisa trata da importância dos recursos minerais no sucesso e no fracasso da colonização espanhola no antigo Guairá. O Antigo Guairá, hoje território do estado do Paraná, era uma província espanhola pertencente à órbita do Paraguai colonial. As cidades e reduções jesuíticas foram destruídas pelos paulistas e desocupadas pelos moradores entre 1629-32. Nos primórdios da ocupação do antigo Guairá predominaram os interesses na procura de metais, importante para consolidar a ocupação espanhola na América. Na ausência destes, optou-se pela exploração da erva-mate. Os principais recursos descobertos pelos espanhóis na região foram ametista e ferro. Os textos dos jesuítas também relatam a presença de depósitos de sal na região. A ametista gerou uma revolta em Ciudad Real Del Guairá em 1569. O ferro, proveniente de lateritas, foi explorado pelos espanhóis e pelos jesuitas em suas missões. A experiência anterior dos espanhóis foi decisiva para esta incipiente cultura do ferro. A ausência de recursos minerais preciosos e a disputa da mão-deobra indígena com os paulistas levaram à desocupação do território.

PALAVRAS-CHAVE Recursos minerais, América do Sul, Guairá, ametista, ferro 


\section{Introdução: do Guairá ao Paraná}

O antigo Guairá (1541-1632) é um território vinculado ao Paraguai colonial, que compreende, de maneira aproximada, a região entre os rios Paranapanema a norte, Iguaçu a sul, Paraná a oeste e Tibagi a leste (figura 1). A região, nos séculos XVI/ XVII, era ocupada por tribos Guaranis e tribos do grupo Jê. As tribos Guaranis situavam-se nos vales dos grandes rios e nas florestas tropicais adjacentes. As nações Jê ocupavam as serras, principalmente as matas de araucária. Segundo avaliações contemporâneas, estima-se para este período uma população de 100 a 300 mil pessoas (Lozano 1755).

O Paraguai colonial se constitui por uma aliança estratégica (e desigual) entre os conquistadores espanhóis e os guaranis da região. A conquista se consolida quando Assunção (antiga Lambaré) é fundada por Juan Ayolas, em 1537, após derrotar os Cario-Guaranis. Aliados aos guaranis, os conquistadores empreendem numerosas expedições para alcançar as regiões ricas em metais preciosos. Perdidas as esperanças de encontrar grandes tesouros na região, os espanhóis se voltam contra seus antigos aliados Guaranis, submetendo-os ao sistema de encomiendas. A (in) submissão das populações indígenas deixa a região em permanente pé-de-guerra contra os espanhóis (Heming 1979).

Desde a conquista do Paraguai, a região do Guairá, que já era cortada por inúmeros caminhos pré-colombianos, virou uma importante região de passagem entre o litoral brasileiro e a cidade de Assunção. A partir de Assunção, foi fundada inicialmente Ciudad Real del Guairá (1557), situada na barra do rio Piquiri no rio Paraná. A segunda vila, denominada Villa Rica del Espiritu Santo mudouse três vezes de lugar (Azara, 1847). Sua primeira fundação deu-se em 1576 em algum lugar do vale do Rio Piquiri, próximo de Ciudad Real. A segunda provavelmente ocorreu no lugar depois denominado Tambo das Minas de Ferro, no Coraciberá (Fig. 1). A terceira fundação ocorre em 1589, no rio Ivaí, próximo a barra do Corumbataí, onde estão as atuais ruínas (Parellada 1997).

Inicialmente, os moradores das vilas tentaram encontrar riquezas minerais. Durante certo tempo, os moradores de Ciudad Real acreditaram no valor das ametistas que ocorrem na região. $O$ ferro era explorado em pequena escala, principalmente em forjas do tipo catalão. Foram descritos inclusive depósitos de salinas na região, na carta ânua de 1628 do padre Antonio Ruiz de Montoya.

Sem achar metais, os moradores (vecinos) das vilas espanholas iniciaram a extração da erva-mate. A erva era explorada utilizando a mão-de-obra indígena, segundo o sistema de encomiendas, também chamado no Paraguai beneficio herbatero. Os índios encomendados, ao final do século XVI, segundo vários documentos listados em Cortesão (Mercê e encomenda de vários índios e caciques do Guairá aos moradores de Villa Rica in Cortesão, 1951) provinham dos vales dos rios Tibagi, Piquiri, Cantu, Iniaí, Iguaçu e Paraná. Estes eram enviados aos ervais da serra de Maracaju, no Paraguai, para a extração da erva-mate.

Como o sistema estivesse comprometido pela resistência indígena, os padres da companhia de Jesus foram convidados pelo governador de Assunção, Hernadárias de Saavedra, a entrar na região e fundar as missões (Charlevoix 1757). Inicialmente duas, cresceram para mais de treze. Os padres, além da resistência dos indígenas em aderir ao projeto reducional, tinham que conter os encomenderos das vilas espanholas e os bandeirantes paulistas. Estes vinham retirar os índios já aculturados para trabalhar em suas plantações de trigo em São Paulo.

O acirramento se dá nos anos de 1628-32, quando as bandeiras paulistas arrasam a maior parte das missões recém-construídas, muitas vezes com a conivência dos espanhóis das vilas e mesmo do governador do Paraguai, Céspedes y Xeria. Os jesuítas decidem retirar as duas últimas reduções do Guairá no final de 1631. Em 1632, os habitantes das vilas espanholas também abandonam a região, que fica praticamente deserta pelos dois séculos seguintes.

Passando para a órbita portuguesa, o antigo Guairá é reocupado posteriormente, como parte do atual estado do Paraná. Esta colonização, que data da segunda metade do século XX, implanta na região um forte setor agro-industrial, com a fundação das cidades de Londrina, Maringá, Cascavel, entre outras.

\section{Objetivos}

Este trabalho trata, a partir de fontes documentais primárias, da história da exploração dos recursos minerais, dentro dos limites do conhecimento mineiro disponível, tanto por parte dos indígenas quanto por parte dos europeus entre os séculos XVI/XVII. O objetivo foi recuperar o maior número possível de fontes históricas primárias e 


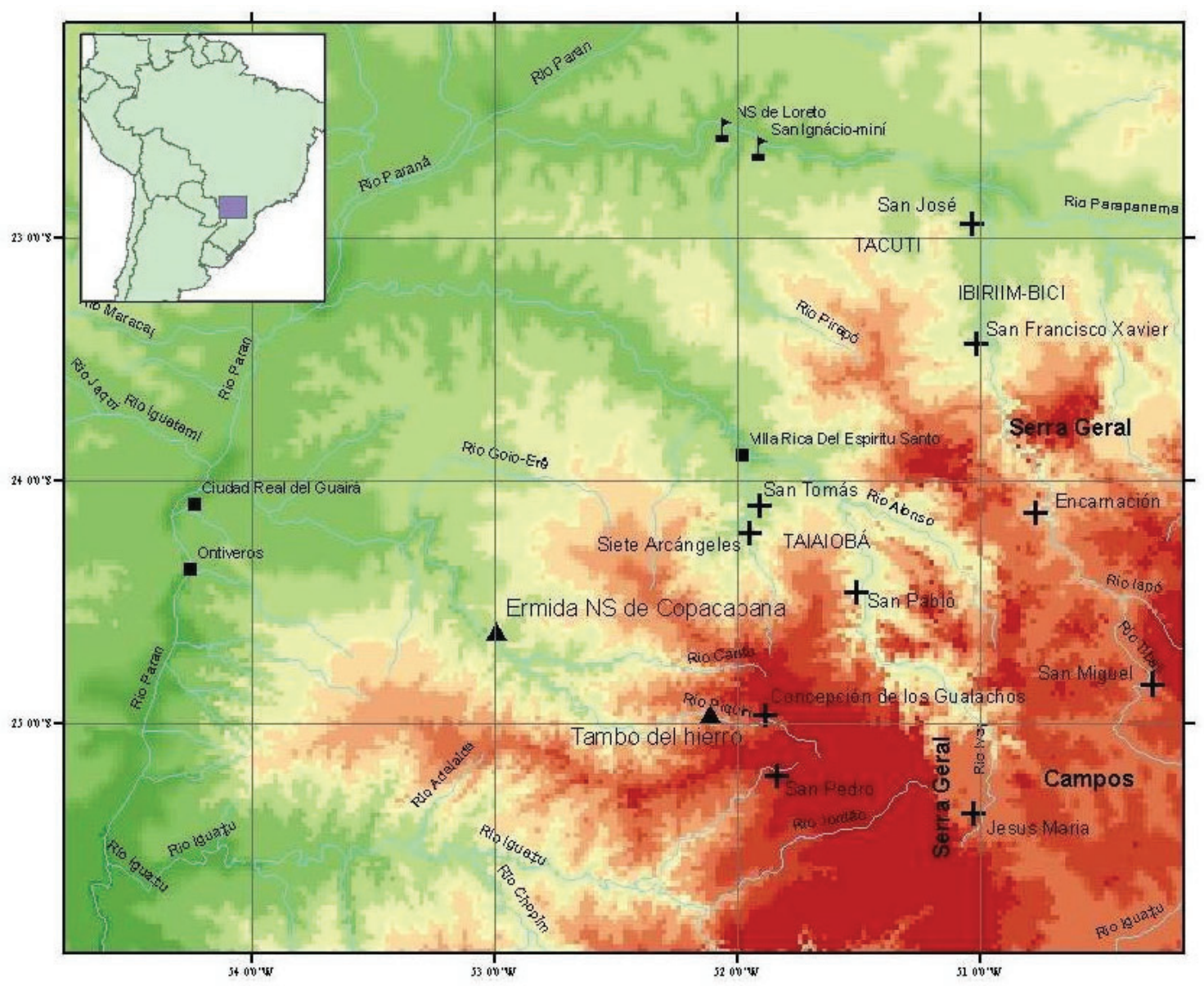

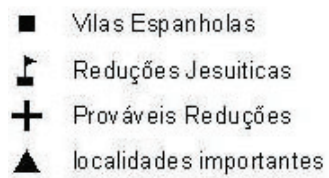

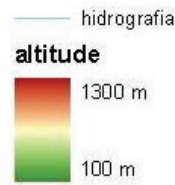

secundárias disponíveis em bibliotecas, arquivos digitais e em novas tecnologias, como os buscadores de internet, que permitem um fácil acesso a fontes antigas e pouco disponíveis, como o são as obras dos séculos XVIII e XIX utilizadas neste trabalho. Com base nestes documentos, introduzimos algumas discussões: 1) Quais os limites impostos pela presença ou ausência dos recursos minerais na sociedade guayreña? ; 2) Como foram aproveitados estes recursos, e qual o significado deste aproveitamento para as populações locais?

\section{Métodos de Pesquisa}

\section{Pesquisa das fontes}

A pesquisa bibliográfica baseou-se em artigos e teses disponíveis em vários institutos e bibliotecas, como a biblioteca do Instituto Histórico e Geográfico do Paraná (IHGP), da Biblioteca Pública do Paraná, e as bibliotecas dos Setores de Ciências Humanas, de Ciências da Terra e Tecnologia e de Ciências Agrárias da UFPR.

Foram recuperadas fontes importantes dos séculos XVI, XVII e XVIII, principalmente com o auxílio da pesquisa pelos Google Books® (http:// books.google.com/). Com o uso destas ferramentas, foi possível utilizar muitas das fontes deste período nos próprios originais, tanto diretamente da rede como no formato PDF.

\section{Fontes primárias impressas}

A principal fonte de documentação primária utilizada neste trabalho está reunida no volume 
Jesuítas e Bandeirantes no Guairá (1549-1640), Manuscritos da Coleção de Angelis, publicada por Jaime Cortesão em 1951. Dele foram extraídas diversas cartas ânuas, outras cartas de jesuítas e documentos oficiais, como as concessões de encomiendas registradas em 1597 em Assunção.

\section{Fontes secundárias impressas dos séculos XVIII e XIX}

As fontes bibliográficas fundamentais de natureza secundária são os livros escritos por jesuítas e naturalistas no século XVIII, das quais extraímos muitas informações e observações fundamentais para o trabalho. São eles:

1) Pedro Lozano, jesuíta, que viveu no Paraguai na primeira metade do século, escreveu a Historia de la Compañia de Jesus de la Provincia del Paraguay (Madrid, 1755). Foi consultado o tomo II, onde contem informações sobre o início do trabalho das missões de Loreto e San Ignácio.

2) Pierre François Xavier de Charlevoix, autor da "Histoire Du Paraguay" (seis tomos), que foi escrita pelo religioso, em 1757. Foi consultado o tomo I, o qual contém muitas informações relevantes sobre a conquista do Paraguai e a entrada dos jesuítas naquela região. O jesuíta nunca esteve em terras Americanas, o que restringe um pouco o julgamento de algumas questões.

3) Martin Dobrizhoffer, jesuíta alemão que esteve no Paraguai em meados do século XVIII e que escreveu " $A$ n account of the Abipones, an equestrian people of Paraguay" (versão em inglês, Londres, J. Murray 1822). Este livro foi importante com respeito aos dados da "revolta" de ametistas e a produção de ferro na província durante o século XVI e XVII.

4) Félix Azara, naturalista e viajante do século XVIII, permaneceu em terras sul-americanas por vinte anos, foi comissário e comandante das expedições responsáveis pela demarcação de limites na América entre a coroa espanhola e a portuguesa. É autor de "Geografia Física y Esférica de las Provincias del Paraguay e Misiones Guaraníes", composta em 1790, e publicada em 1904 em Buenos Aires. Foram utilizadas como fonte secundária os apontamentos do livro de Azara, "Descripción e História del Paraguay y del Río de la Plata", editada pela primeira vez em 1847 , onde o autor utiliza-se de documentos históricos dos Arquivos de Assunção, Corrientes, Santa Fé e Buenos Aires.

\section{Guairá: una província sin metales?}

Uma dos problemas mais sérios que os conquistadores enfrentam na região paraguaia é a ausência de metais preciosos, o que os obriga a viver de maneira muito diferente e bastante mais simples que os espanhóis do Peru.

Segundo o testemunho do padre Dobritzhofer, no século XVIII, muito embora utensílios de prata possam ser vistos nas casas e igrejas dos espanhóis, assim como nas missões Guaranis, nem mesmo uma reles moeda de cobre é batida no Paraguai. Todos os metais vêm do Chile ou do Peru (Dobritzhofer 1822).

De fato, o grande produto da região Paraguaia passa a ser a erva-mate, ou caá. A produção de mate era feita nos ervais da serra de Maracaju, entre os atuais Paraguai e o estado de Mato Grosso do Sul, região rica em ervais nativos. Imagina-se que a ervamate era conhecida há muito pelos guaranis, utilizada, como o tabaco, em rituais religiosos. Quando os espanhóis conhecem as propriedades medicinais da erva-mate, começam igualmente a utilizá-la. Em breve, o uso da yerba do paraguay estaria difundido do Peru ao Prata, transformando-a num dos mais bem-sucedidos produtos de exportação.

Neste contexto, Villa Rica Del Espiritu Santu nasce para ser um ponto de apoio para riquezas minerais, como bem aponta seu nome. No entanto, os habitantes de Villa Rica, assim como os de Ciudad Real, sempre foram muito pobres. A grande esperança inicial dos habitantes do Guairá, sobretudo os de Villa Rica, eram os minérios. A busca foi intensa. Segundo o testemunho do padre Charlevoix, "Muito [Rui Diaz] Melgarejo, assim como seu genro Manoel de Frias, fizeram grandes serviços de exploração, com poucos resultados" (Charlevoix 1757). Para Charlevoix, a nova Villa Rica, relocada para perto de Assunção a partir da destruição do Guairá no século XVII, "ganhou muito por não contar com minas imaginárias, levando seus cidadãos a suprir suas necessidades de formas mais convenientes e seguras" (Charlevoix op.cit).

\section{As ametistas}

As ametistas são gemas muito comuns, encontradas em geodos de níveis específicos, dentro de 
alguns dos derrames basálticos na Província Magmática Serra Geral, nos estados do sul do Brasil (para maiores detalhes geológicos destas ocorrências, ver Gomes 1996, Scopell 1997, DNPM, 1998). Nas terras do Guairá estas rochas chamaram desde logo a atenção. Os espanhóis chamavam os geodos guayreños de cocos de mina. A ocorrência de ametistas e de geodos, "hacia Paraguay y Buenos Aires", foi citada inclusive por Álvaro Alonso Barba em seu famoso livro "Arte de Los Metales", inicialmente publicado em 1640 (Barba 1817). No século XVIII, Dobrizhoffer (1822) descreve os geodos como pedras profundamente enterradas no solo, algumas vezes redondas e outras vezes ovais. A superfície é áspera e dura, de cor escura e tamanho variando de uma romã a uma cabeça humana. Dentro da carapaça externa do geodo ocorrem pequenos cristais de várias cores. Charlevoix (1757) descreve que os cristais "não são todos da mesma cor, a maioria são vermelhos, [embora existam] exemplares verdes e violetas. Eles são esculpidos de uma maneira tão variada e regular, que quase não se crê que sejam obras da natureza". Diziam que os cocos, prenhes com este tipo de pedras, estouravam com um som semelhante ao de um canhão (Charlevoix op.cit). Alguns joalheiros da época, ainda segundo padre Charlevoix, julgaram que as ametistas eram tão valiosas como as pedras da Boêmia. Por um breve momento, parece que os habitantes de Ciudad Real haviam achado sua sorte.

Para uma geração de colonos sedenta de riquezas minerais que os tirassem da pobreza, as ametistas eram um sonho. Assim que se soube dessa descoberta, "publica-se que o Paraguai era cheio de ametistas, granadas e esmeraldas" (Charlevoix op.cit).

Assim que se descobrem as ametistas, os espanhóis se entusiasmam com a perspectiva de riqueza, e muitos estão a ponto de abandonar seus estabelecimentos para levar pedras à Espanha, onde julgam fazer grande fortuna (Lozano 1755). Em 1569, os moradores de Ciudad Real se rebelam contra o governador Alonso Riquelme, e carregados com quantidades consideráveis destes cristais, "como si fueran ametistas, topacios y crisólitas", tratam de voltar à Espanha pelo caminho do Brasil. O capitão Rui Díaz Melgarejo vai atrás dos fugitivos, e os convence a voltar para Ciudad Real (Lozano, op.cit). Foi o fim da "Revolta das ametistas" uma das tantas que abalaram a região nestes primeiros tempos da colonização espanhola. As ametistas do Guairá acabaram sendo somente um sonho de riqueza. Segundo um ditado espanhol, citado por Dobrizhoffer (1822), comentando estes acontecimentos cerca de dois séculos depois: "El ciego sonaba que veia, y sonaba lo que queria".

Hoje, o comércio de ametistas, na forma de geodos, é um importante recurso mineral no sul do Brasil. A extração concentra-se no noroeste do Rio Grande do Sul, em níveis específicos de derrames basálticos da formação Serra Geral. O distrito possui reservas totais de $620 \mathrm{t}$ no ano de 2005 (DNPM 2010a), quando foram comercializadas $455 \mathrm{t}$ de geodos brutos e $378 \mathrm{t}$ de geodos beneficiados.

Não existem dados sobre a produção de ametistas no Paraná. Porém, segundo o DNPM (2010b) existem no presente 41 áreas de exploração registradas. A maior parte no rio Chopim, as outras áreas dispersas pela região de ocorrência dos derrames basálticos.

\section{Ferro}

São verificados em todas as vilas espanholas e nas reduções jesuíticas de Loreto e San Ignácio muitos fornos, com escória de fundição associada. O forno descrito por Claudia Parellada em Villa Rica é do tipo catalão (Parellada 1991). Este tipo de forno, surgido no século XV, é um forno do tipo baixo que trabalha com grande consumo de carvão (Araújo 1996). Têm foles manuais, que foram mais tarde substituídos por foles movidos por rodas d'água. Este tipo de forno não alcança a temperatura de fusão do ferro, a $1535^{\circ} \mathrm{C}$. Com isso o material, após aproximadamente 4 horas de fogo, forma uma massa pastosa, ou lupa. A lupa é então retirada e martelada para separar a escória (Araújo op.cit).

Pelas ruínas de Ciudad Real são encontrados fragmentos de cerâmica associados a escoria mineral, carvão vegetal e lascas de rocha, geralmente de arenito Botucatu silicificado ou pedaços de limonita. Os registros arqueológicos mostram que estas escórias são produto de fusão parcial de ferro e manganês, porém sem redução de óxidos, causada por deficiência de calor e pela ausência de um composto redutor (Chmyz 1963).

No século XVIII, nos Sete Povos das Missões, hoje Rio Grande do Sul, o Padre Sepp extraiu ferro de uma rocha chamada itacana, ou itacuru (Dobrizohefer 1822). Era uma pedra muito dura, com pequenas manchas escuras. Quando colocou as pedras no forno, padre Sepp notou que as pequenas manchas pretas eram de um ferro muito 
bom. Entretanto, estas pedras eram muito raras e o ferro então utilizado nas missões precisava ser trazido de fora.

Acredita-se que o principal minério de ferro do antigo Guairá era a limonita, uma mistura dos minerais goetita $\left(\alpha \mathrm{HFeO}_{2}\right)$ e lepidocrocita $\left(\gamma \mathrm{Fe}_{2} \mathrm{O}_{3}\right)$, com um teor médio de $60 \%$ de ferro. É um minério comum formado em zonas pantanosas (bog iron) de ambientes superficiais redutores, ou em horizontes de lateritas de ferro formado em regiões de solos tropicais. As lateritas de ferro formam espessas carapaças nos solos de algumas regiões do Brasil central, e são lá conhecidas por canga, ou itapioacanga.

Onde era extraído este ferro? A mais bem documentada procedência era a localidade do Tambo do Ferro, localizada, segundo Chmyz (1963) no alto vale do rio Piquiri (ver figura 1). Por exemplo, na chegada dos padres Cataldino e Maceta, em 1610, Rodrigo Melgarejo adianta-se para o mineral de ferro, ou seja, a mina do Tambo, para pegar machados e alavancas para os índios (Lozano 1755). O padre Antônio Ruiz de Montoya, na carta ânua de 1628, cita o local por várias vezes, ao falar da redução dos índios Gualachos:

1) cita a presença do capitão Gerônimo Merino, "Teniente del Tambo" que o estava ajudando ali nas "minas de hierro";

2) informa em outro trecho que iria ao Tambo com "ropas a buscar cuñas" e reclama do cabildo de Villa Rica, que cobrou pelo preço do ferro o dobro do preço de 50 anos atrás;

3) a carta é assinada no "Tambo de Curaciberá y minas del hierro" em 2 de julho de 1628.

Em 1630, em esboço de outra carta ânua, Montoya cita que uma viruela, possivelmente uma epidemia de varicela, tomava conta da redução dos Gualachos. "Como esta reduccion está junto ao tambo onde los españoles cultivam el hierro" (Carta ânua, op. cit), Montoya teve que ajudar tanto índios quanto espanhóis com os cuidados ou as unções.

Segundo o dicionário on-line da Real academia Espanhola, a palavra Tambo é derivada do quíchua tampu, e tem o sentido, na maior parte da América andina, de pouso ou albergue (Real Academia 2010). Na Amazônia brasileira e peruana, também significa palhoça, ou barracão, segundo o Dicionário Aurélio (Ferreira 1982). Nos países platinos, e também no Rio Grande do Sul, tem também o significado de estábulo.
Montoya descreve a localidade de Tambo como um mineral de ferro. Esta palavra, nos séculos XVIXVII, também se aplicava às zonas mineiras, ou minas. Ou seja, uma região onde ocorria o ferro, onde o ferro era lavrado e ou também forjado. A indicação de que o cabildo de Villa Rica impunha preços no ferro ali extraído mostra que o ferro deve ter sido uma atividade comercial importante, embora fosse predominantemente de escambo. O Tambo era também um lugar onde se vendiam cunhas, machados e outras ferramentas. Como não se sabe ao certo a localização deste lugar, não se tem uma idéia clara de que tipo de minério era lavrado e/ou forjado. No entanto, o Tambo era também um lugar de passagem, ou pouso. Por outro lado, a denominação Coraciberá, nos escritos de Montoya, nos leva também a crer que o Tambo pode ter sido uma das localizações prévias de Villa Rica, provavelmente a segunda.

Algumas ocorrências de minérios de ferro têm sido recentemente descritas em rochas basáticas da Província Magmática Serra Geral, provavelmente carapaças lateríticas. Embora tenha sido objeto de sérias dúvidas quanto à viabilidade econômica, diversas áreas de pesquisa para ferro foram requeridas nos municípios de Londrina e Tamarana, vale do rio Tibagi (DNPM 2010b).

\section{Salinas}

Outro bem mineral citado nas cartas ânuas são as salinas. Padre Montoya cita a "descubierta de uns salinas dos dias de camino desta reduccion [de La Encarnación]" (Carta ânua Pe Montoya, 1628), para onde ele ia levar machados e ferramentas para fazer uma nova redução. A região destas salinas fica provavelmente no Vale do Rio Tibagi, abaixo da Serra dos Agudos, em terrenos de rochas de idade Paleozóica. Montoya relata também que os índios Ibiaiara e os Gualachos - nações do grupo Jê - "terian noticias de que [h] ay tambien salinas ao modo de las del Paraguay".

Há outras referências, também, à presença de salitre. No manuscrito do Padre Araújo (162223), transcrito em Ferreira (1960), relata que um membro da expedição de André Fernandes (161315) descobriu no vale do rio Iabeberi (Tocantins) "um mineral de salitre que conheceu mui bem pela experiência que dele tomara entre os castelhanos das partes de Vila Rica". Se estes "minerais de salitre" conhecidos pelos villariqueños seriam 
procedentes do Paraguai ou da região do Guairá é um ponto que permanece em aberto.

Não se sabe o que seriam exatamente estas salinas guayreñas, nem sua provável composição ou qual seria sua forma de ocorrência. As salinas que Montoya cita ao final, similares às do Paraguay, seriam provavelmente iguais às lagoas salinas do Pantanal, conforme descrito por Fernandes (2007) para a região de Nhecolândia. No entanto, as salinas próximas da redução de Encarnación poderiam ser simplesmente eflorescências salinas, ou "barreiros", (Eschwege 1832, Barbosa 1973), comuns em diversas localidades do interior do Brasil. Embora de valor limitado nos dias de hoje, estas áreas foram muito importantes na disseminação de rebanhos bovinos no Brasil colonial. Também eram muito importantes para os caçadores, que faziam esperas nestas áreas de salinas para caçar animais silvestres que vinham buscar sal.

\section{Recursos Minerais: ocupação e subsistência}

Os recursos minerais disponíveis nos séculos $\mathrm{XVI} / \mathrm{XVII}$ pelas populações espanholas e indígenas do Guairá são determinantes para se analisar o caráter da conquista e dos esforços de ocupação do território americano pelas populações castelhanas. A ausência de ouro e prata no Paraguay obriga os colonos a buscar a sobrevivência na extração do mate, o qual se torna o produto paraguaio por excelência nos séculos seguintes, baseado principalmente na exploração da mão-de-obra indígena segundo o sistema das encomiendas .

Neste contexto, a escolha da erva mate como produto de exportação colonial foi muito semelhante à opção pelo açúcar adotada pelos portugueses do Brasil. De fato, há uma semelhança muito grande entre Assunção e a São Paulo dos quinhentos, como observado, entre outros, por Schwartz (2002).

Neste contexto, todo o episódio da "Revolta das Ametistas" em Ciudad Real está situado neste primeiro momento de busca de alternativas para uma riqueza fácil e rápida. Tratava-se da primeira geração de colonos, que haviam sido desalojados para o Guairá por causa das lutas pelo poder em Assunção e, também, atraídos pela presença de abundante mão-de-obra indígena no território (Lozano op.cit).

A busca do ferro esteve ligada a interesses mais pragmáticos. Verifica-se que em todas as vilas espanholas e nas subseqüentes reduções jesuíticas houve algum tipo de trabalho metalúrgico, ainda que as fontes do ferro fossem escassas. Parece sugestivo que a provável localização do mineral do Tambo fosse uma região do planalto basáltico, na bacia do alto Piquiri, onde são comuns as superfícies laterizadas, provável fonte do ferro explorado neste período.

Ressalte-se também o conhecimento que os espanhóis tinham sobre a metalurgia do ferro, principalmente os originários dos países bascos (Riart 2001). Havia muitos da primeira leva de conquistadores provenientes de Biscaia, região rica em jazidas de ferro. O mais ilustre dos biscainhos foi, sem dúvida Domingos Martinez de Irala (1509-1557), um dos primeiros governadores do Paraguay (Azcona \& Douglas 2004). Embora não fosse biscainho, o fundador de Ciudad Real e Villa Rica, Rui Diaz Melgarejo, também tinha conhecimentos de metalurgia do ferro, conforme atestado por Lozano (op.cit).

O ferro também foi um instrumento importante na conquista espiritual dos povos indígenas. $\mathrm{O}$ machado de ferro e a redução sempre estão juntos (Carle 1993). Embora os Guaranis pré-conquista tivessem contato com os povos metalúrgicos da América, o uso de metais era bastante limitado, pois as suas necessidades culturais não propunham o uso de metais da mesma forma que eram utilizados pelos povos metalúrgicos sul-americanos.

Com a chegada dos europeus, a cultura do ferro disseminou-se e criou uma forte dependência Guarani, que permanece até hoje. A possibilidade de manutenção dessa tecnologia do ferro só foi possível com a instalação dos povoados missioneiros. Nas reduções, ocorre a mudança do status do indígena para ferreiro. Com essa alteração, o projeto jesuítico de consolidação das missões ganha um importante atrativo. Pela posse de instrumentos de ferro, muitas tribos eram atraídas para as reduções, mesmo que não estivessem interessadas, como diziam, em proteção contra os espanhóis.

As forjas indígenas evoluíram rapidamente, passando de um estágio medieval a um estágio "moderno" em poucos anos. Analisando os metais das coleções arqueológicas de São Nicolau, São Miguel e São Lourenço, nos sete povos das missões (RS), verifica-se que os objetos de metal apresentam um padrão construtivo e doméstico altamente sofisticado para o período (Carle op.cit).

Na redução de São João Batista, durante o 
século XVIII, segundo Cláudio Carle, a maioria das peças é de ferro martelado e matriz aberta, técnica bastante comum na época. A presença de manganês nas rochas ferríferas do planalto das missões indica que estes objetos tenham sido produzidos no interior do povoado, pela fusão das rochas no forno da redução (Carle op.cit).

Os fornos mais simples foram sendo utilizados com grande freqüência nas oficinas e os fornos de fundição foram sendo gradativamente introduzidos. A difusão das novas tecnologias chega à América e os maiores utilizadores são encontrados nas missões. As oficinas, além de produzir elementos necessários para os trabalhos no campo, ornamentações e outros, produzia também a maioria das ferramentas para os artesãos das oficinas.

No século XVIII, muito ferro estava sendo levado pelos espanhóis em navios, e eram vendidos a preços muito elevados. Nas cerimônias de casamento dos jovens Guaranis, estes ganhavam de presente dos jesuítas, uma faca para usar à mesa. Segundo Dobrizhoffer(1822), estes presentes eram muito mais caros do que um contemporâneo europeu pudesse imaginar.

Já quanto às "salinas" citadas por padre Montoya, parece que os jesuítas não tiveram tempo de estruturar qualquer tipo de exploração, pois as invasões dos paulistas em busca de Guaranis a cativar se intensificaram nos anos seguintes (1628-1632). Os ataques paulistas, visando principalmente cativos para trabalhar em suas lavouras de trigo no planalto paulistano (Monteiro 1994), desestruturam o sistema guayreño das encomiendas. A ameaça paulista e a passividade e cumplicidade dos moradores de Ciudad Real e Villa Rica forçam os jesuítas a se retirarem com os indígenas das missões de Loreto e San Ignacio para as reduções mais ao sul, levando ao despovoamento do Guairá. Privados da mão-deobra dos indígenas, os colonos espanhóis abandonam as vilas. Parte vai ao Paraguai, embora muitas destas famílias tenham se mudado também para São Paulo. O território então abandonado pelos espanhóis passaria, nos séculos seguintes, a fazer parte da área sob o domínio português.

Parece irônico que foi na região do vale do Tibagi, tão devassada por padres jesuítas e encomenderos guayreños e villariqueños, que tivessem sido encontrados os recursos minerais que estes tanto ansiaram. De fato, em 1755, foram descobertos diamantes e ouro neste rio (Leão 1926). Embora de pequena monta, estes recursos, um século e meio antes, poderiam ter feito a diferença nos esforços de ocupação da área por parte dos espanhóis de Assunção.

\section{Conclusões}

Os recursos minerais, principalmente os metais preciosos, foram um importante motor da conquista ibérica, em tempos modernos. A região Paraguaia, no entanto, não continha recursos minerais suficientes para justificar um tipo de exploração econômica similar ao que os espanhóis desenvolveram no planalto andino.

As ametistas representaram principalmente os anseios de riqueza por parte dos primeiros espanhóis, ainda na época da conquista. $\mathrm{O}$ desengano de seu valor foi um duro golpe nos sonhos dessa primeira geração de colonos. O ferro, por outro lado, era uma necessidade, tanto na fabricação de ferramentas na própria região quanto na troca e nas boas relações com os povos guaranis circunvizinhos. A exploração do ferro realizada no Guairá foi facilitada pela larga experiência dos espanhóis na mineração e siderurgia na península ibérica. Estes aspectos somados se traduzem no pioneirismo espanhol das atividades mineiras e siderúrgicas no novo continente, em contraste com seu desenvolvimento mais lento da América portuguesa.

\section{Agradecimentos}

Os autores agradecem aos dois revisores anônimos, pelos comentários e críticas recebidos, que melhoraram em muito a qualidade do presente artigo.

\section{Referências Bibliográficas}

\section{Fontes primárias impressas}

Carta ânua do padre Antonio Ruiz, superior da missão do Guairá, dirigida em 1628 ao padre Nicolau Durán, Provincial da Companhia de Jesus. In: Cortesão J. 1951. Manuscritos da coleção De Angelis: Jesuítas e Bandeirantes no Guairá. Biblioteca Nacional, p. 259-298.

Mercê e encomenda de vários índios e caciques do Guairá aos moradores de Villa rica. In: Cortesão J. 1951. Manuscritos da coleção De Angelis: Jesuítas e Bandeirantes no Guairá. Biblioteca Nacional. p. 439-441. 


\section{Fontes secundárias}

Araujo L.A. 1996. Manual de Siderurgia. Arte \& Ciência, $472 \mathrm{p}$.

Azara F. 1847. Descripción de la historia del Paraguay y del Rio de la Plata: Buenos Aires, Sanchiz. Google books, Harvard University. URL: http://books. google.com.br/books. pesquisa em 17/03/2010

Azcona J.M., Douglass W. 2004. Possible paradises: Basque emigration to Latin América University of Nevada Press. 568 p.

Barba A.A. 1640. Arte de los metales, en que se enseña el verdadero beneficio de los de oro, y plata por azogue. El modo de fundirlos todos, y como se han de refinar, y apartar unos otros. Compuesto por el licenciado Alvaro Alonso Barba. URL: http://books.google. com.br/books. Pesquisa em 15/03/2010.

Barbosa R.L. 1973. Perfil analitico do sal. Rio de Janeiro, DNPM. 47 p.

Carle C.B. 1993. A metalurgia como estratégia missioneira. In: Simpósio Nacional de Estudos Missioneiros, 10, Santa Rosa, RS. Anais..., Santa Rosa. p. 479-485.

Charlevoix P.F. 1757. Histoire du Paraguay, tome I. URL: http://books.google.com/books. Pesquisa em 17/03/2010.

Chmyz I. 1963. Contribuição arqueológica e histórica ao estudo da comunidade espanhola de Ciudad Real do Guairá. Curitiba: Revista de História, 2: 77-114.

Departamento Nacional da Produção Mineral (DNPM) 2010a. Anuário mineral brasileiro. Parte III - Estatísticas Por Substância: http://www. dnpm.gov.br/assets/galeriaDocumento/AMB2006/ substancia\%20f-m.pdf (pesq em 17/08/2010).

Departamento Nacional da Produção Mineral (DNPM) 2010b. Informações Geográficas da Mineração (SIGMINE). http://sigmine.dnpm.gov. br/ (pesq em 17/08/2010).

Departamento Nacional da Produção Mineral(DNPM) 1998. Ametistas do Alto Uruguay: aproveitamento e perspectivas de Desenvolvimento. Brasília, Série Difusão Tecnológica no 6. 260 p.

Diccionário online da Real Academia Espanhola. Verbete: tambo. URL: http://buscon.rae.es/draeI/ . pesquisa 17/03/2010.
Dobrizhoffer M. 1822. An account of the Abipones, an equestrian people of Paraguay. Londres, J. Murray. URL: http://books.google.com.br/books. pesquisa em 17/03/2010.

Eschwege W.L. 1832. Pluto Brasiliensis. São Paulo/Belo Horizonte: Edusp/Itatiaia. 1979. 210 p.

Fernandes E. 2007. Organização espacial dos Componentes da Paisagem da Baixa Nhecolândia - Pantanal de Mato Grosso do Sul. São Paulo, Brasil: 177. Tese doutorado, Fac. de Filo., Letras e Ci. Humanas/ USP.

Ferreira M.R. 1960. O Mistério do Ouro dos Martírios. Biblios, São Paulo, 470p.

Gomes M.E.B. 1996. Mecanismos de resfriamento, estruturação e processos pós-magmáticos em basaltos da Bacia do Paraná: região de Frederico Westphalen (RS) - Brasil. Tese, UFRGS, 219 p.

Hemming J. 1979. Ouro Vermelho: A Conquista dos Índios Brasileiros. São Paulo, EDUSP, 780 p.

Lozano, P. 1755. Historia de la Compañia de Jesus de la Provincia del Paraguay. Madrid, 1755. URL: http://books.google.com.br/books pesquisa em 17/03/2010.

Monteiro J.M. 1994. Negros da Terra. Índios e bandeirantes nas origens de São Paulo. São Paulo, Cia das letras. 300 p.

Novo Dicionário da Língua Portuguesa Aurélio Buarque de Holanda Ferreira. Rio, Nova Fronteira, $1^{\mathrm{a}}$.

Parellada C. 1997. Um tesouro herdado: os vestígios arqueológicos da cidade colonial espanhola de Villa Rica Del Espiritu Santo/Fênix, PR. Curitiba UFPR, $211 \mathrm{p}$

Riart O.P. 2001. Histoire dês Mines dans La Peninsule Iberique. In: Serrano Pinto (ed) INHIGEO meeting - Portugal. Centro de Estudos de Historia da Filosofia e da Técnica, Universidade de Aveiro. p. 38-50.

Schwartz S.B. 2002. A América Latina na Época Colonial. São Paulo, Record. 543 p.

Scopel R.M. 1997. Estudo dos derrames basálticos portadores de ametista da região de Ametista do Sul, RS, Brasil. Alteração pós-magmática. 219 p., (Tese, Dout.)Instituto de Geociências, Universidade Federal do Rio Grande do Sul, Porto Alegre. 